\title{
Alignment of E-Business with SMEs' Strategies in Northeast of Mexico
}

\author{
Norma Pedraza', Maribel Guerrero²,Jesús Lavín ${ }^{3}$
}

\begin{abstract}
The alignment of e-business with business strategy is a theme that has gained interest among managers and researchers in the area. In this sense, the objectives of the present study are: (i) to identify the existing perspective of the strategic alignment in the SMEs; (ii) to find out the perception that the SMEs' managers have about the criteria that determine the maturity level of the e-business alignment with the business strategy; and (iii) to identify the existing relationship between the perspective of the e-business alignment with the criteria that promotes its alignment with the business strategy. This study adopted the models developed by Henderson and Venkatraman (1993, 1999), Luftman (2000) and Sledgianowski, Luftman and Reilly (2006). Methodologically, a 52 item questionnaire was administered to a sample of 82 managers of enterprises located in the northeast of Mexico. The results present relevant implications for the strategic management of private organizations.
\end{abstract}

Keywords: Mexico; strategic alignment; e-business; SMEs.

\footnotetext{
1,2,3 U.A.M. de Comercio y Administración - Victoria Universidad Autónoma de Tamaulipas Centro Universitario “Adolfo López Mateos”, C.P.87I49 Cd.Victoria, Tamaulipas. México. Telephone and Fax Number: (834) 31817 56. Email: napedraza@uat.edu.mx, marguerrero@uat.edu.mx, jelavin@uat.edu.mx
} 


\section{Introduction}

Over the last decades, the accelerated development of the information technologies (IT) has brought important changes in our daily, working, business and market life. Nowadays, even the ways of doing business are changing, as it is possible to make arrangements, transactions and processes online such as electronic banking, electronic commerce, long-distance education, among others. According to Nieto and Fernández (2006) this has been possible because technology has turned itself into a standardized and accessible resource which is currently being applied to enable or support a variety of e-business processes ${ }^{4}$. It is because of the above mentioned that the issue of the alignment of the IT and the business strategy is of great interest to managers and researchers. For example, it has been observed the need to analyze the impact that the IT can have on productivity, competitiveness, innovation, costumers' satisfaction, on the administration and control in the organizations (Torkzadeh, Koufteros and Doll, 2005; Monge, Alfaro and Alfaro, 2005). In this context, it is required to assess the way in which enterprises manage their technological resources in order to activate their processes and to determine whether these are aligned with the business strategy. With respect to this, scholars such as Clempner and Gutiérrez (2002) and Noor and King (2006) state the need for the existence of an alignment between business processes and business strategies, and not unarticulated actions.

As a result, researchers agree on the importance of analyzing the issue of the strategic alignment (Henderson and Venkatraman, 1999; Luftman, 2000; Beeson, Al Mahamid and Lane, 2003; Computer Sciences Corporation, 2005; Torkzadeh et al., 2005; Brodbeck et al., 2005; Sledgianowski et al., 2006) and identifying the way in which such alignment contributes to the highest levels of organizational performance (Chan et al., 1997; Rivard, Raymond, Verreault, 2006). There have been a series of studies which have contributed theoretically and empirically to the development of this research area
(Henderson and Venkatraman, 1993; Brynjolfsson and Hitt, 1995; King and Teo, 1997; Kearns and Lederer, 2003; Luftman, 2000; Brodbeck et al., 2005; Slaughter et al., 2006; Sledgianowski et al., 2006). In the case of Mexico, research has focused on the e-business practices (Erosa and Arroyo, 2003) and the relationship between the alignments of e-business with business strategy (Pedraza, 20II). In the particular case of the strategic alignment there are various approaches to its analysis based on knowledge management (AIAmmary and Fung, 2008); the IT/business strategy alignment model (Henderson and Venkatraman, 1999; Luftman, 2000; Brodbeck et al., 2005; Sledgianowski et al., 2006); the software development processes approach (Slaughter et al., 2006); and the information intensity of value chain model (Kearns and Lederer, 2003).

However, there is no research on the perception that the SMEs managers have regarding the strategic alignment of the business processes and to identify the criteria that contribute for this to take place. Therefore, the main aims of this research are: (i) to identify the perspective of the existing strategic alignment in the SMEs; (ii) to identify the perception that the SMEs managers have about the criteria used to determine the degree of maturity of the e-business processes with the business strategy; (iii) to identify the existing relationship between the perspective of the e-business alignment with each of the criteria that promotes its alignment with the business strategy. In order to achieve these aims, the IT/business strategic alignment model developed by Henderson and Venkatraman (1993 and 1999) is adopted, along with the criteria used to determine the degree of e-business alignment maturity with the business strategy proposed by Luftman (2000) and Sledgianowski et al., (2006).

Methodologically, a 52 item questionnaire was developed based on this framework. It was administered to a sample of 82 intermediate and high level managers of different enterprises located in the northeast part of Mexico. The

${ }^{4}$ The concept of e-business processes refers to the transactions, arrangements, and the group of business-related activities supported by computers and mediated by telecommunication networks (Johnston and Wright, 2004). When we talk about business processes we refer to the group of activities, the ways of organizing, coordinating and focusing the work to design a tangible (product) or intangible (service) good, keeping the final customers or a particular market in mind. This implies that the management needs to provide flows of products, material, cash, information and knowledge (Davenport, 1993; Lambert and Cooper, 2000).

ISSN: 07I8-2724. (http://www.jotmi.org) 
data analysis was conducted through the use of descriptive statistics techniques in order to determine the profile of the analyzed enterprises. In addition, multivariate statistics through the structural equations model were used to identify the existing relationship between the perspective of alignment and its elements, which are identified in this study as criteria. It is estimated that the results have relevant implications for the strategic management of public (government, higher education institutions) and private organizations (software and hardware providers, IT managers and business owners). These implications can be used to promote and implement collaboration and coordination spaces among these actors and to develop policies of access, adoption and use of IT in order to enable the e-businesses aligned with the business strategy.

\section{Alignment of the e-business processes with the business strategy}

Nowadays, the alignment of the e-businesses and business strategies is regarded as necessary. However, Feurer et al. (2000) warn that this is not an easy, let alone clear, job. It is estimated that the business strategies are defined first and then the operations, processes and support strategies are aligned to them, with the technology strategy being one of them (Henderson and Venkatraman, 1999). Other authors such as Montiel et al. (2009) studied the relationship existing between technology strategy and performance of a small company in Spain; and Marques and Ferreira (2009) evaluating the factors that determine firms' innovative capacity, and the subsequent influence on SMEs performance in Portugal. Particularly, Montiel et al., (2009) founded three steps: initially, the firm must recognize the dynamic of the context in which it operates, so that it knows the different kinds of strategies that are possible to undertake; secondly is the change of the structure in order to implement the strategies; and finally, the firm must find a mechanism to protect the profits. With respect to this, Peak, Guynes and Kroon (2005) explain that the alignment involves the good use of decisions related to these technological resources in order to meet the strategic, tactic and operative objectives of organizations.

The e-business processes are forcing this alignment with the business strategy, as their development requires important changes in both internal and external relationships of an Enterprise. What is interesting here is that it is through this process that the creation of value through the use of IT in the business processes and the performance of inter-organizational transactions are achieved (Del Águila and Padilla, 200I). In this context, the alignment of the IT and business strategies can present the following four perspectives proposed by Henderson and Venkatraman (1993 and 1999) and Luftman (2000):

(i) The strategic execution perspective is characterized by the fact that the business strategy defines the design and pathway of the business, as well as the management of the IT infrastructure. In other words, the manager designs the business strategy and the IT manager is only responsible for putting into practice the products and services of such technological infrastructure in order to support the business strategy as defined by the administration. The measurement criteria could be financial profits, process efficiency or both.

(ii) The technological potential perspective, unlike the previous one, presents the development of an IT strategy in response to a business strategy. That is to say, the role of the IT manager at the enterprise starts gaining importance for the organization, perceiving this technological infrastructure in the enterprise as an investment center. Among the measurement criteria are technological leadership, and new services available to customers.

(iii) The competitive potential perspective refers to the idea that the role that IT plays in the Enterprise has become a key factor in the business strategic management, as it is considered a strategic resource which enables the exploitation of the capacities of these resources in order to have an impact on new products and services (scope of the business, as stated in the mission and vision statements) and even on the qualities of business strategy (distinctive qualities). In this perspective, the adaptation of the business strategy via the emerging capacities of such technological platform is permitted; the measurement criteria would be competitive advantage, income raise, and the improvement of the relationship with customers.

(iv) The service level perspective makes reference to the creation of a world class IT service organization. The specific role of the top management is to prioritize the assignment of resources within the organization and in the technological market, whereas the role of the one in charge of the technological infrastructure is that of the executive leader. His main job is to ensure the internal technological service is successful based on 
the top management's operational requirements. The performance criterion to measure this dimension would be customers' satisfaction.

Similarly, it is important to know the criteria that promote the strategic alignment maturity of the e-business processes which are carried out within the enterprises. With respect to this, Luftman (2000), Sledgianowski et al. (2006) and Brodbeck et al. (2005) agree that all these criteria are inter-related to communications, value measurement, governance, partnership, technology and human resources (Figure I). As a result of this, the alignment between the e-business processes and the business strategy is conceptualized in this research based on the Strategic Alignment Maturity model proposed by Luftman (2000); Sledgianowski et al., (2006) y Brodbeck et al., (2005). This is so because such a model includes a series of criteria and practices (Appendix I and II) which incorporate the theoretical concepts on the topic using a managerial approach that promotes the alignment.

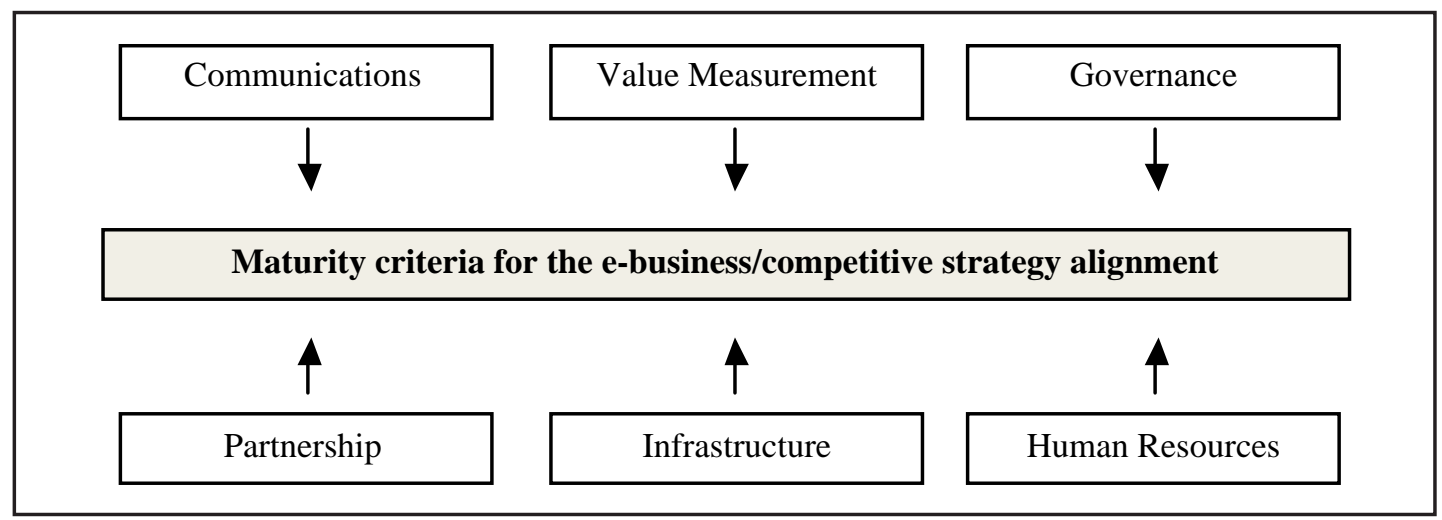

Figure I. Strategic Alignment Maturity model/ Source: Design base don Luftman (2000), Brodbeck et al. (2005) and Sledgianowski et al. (2006)

Authors such as Bruce (1998), Luftman (2000), Reich and Benbasat (2000), Brodbeck et al. (2005), Peak et al. (2005) and Sledgianowski et al. (2006), state that communications is one of the maturity criteria for the promotion of strategic alignment. They argue that when the top management of the Enterprise does not communicate the aims and objectives of the organization to the IT department dissatisfaction about the contribution that this technology makes is produced. This may be due to the lack of/or little communication as well as the impossibility of an effective information sharing process between the top and the IT management areas. In this context, Reich and Benbasat (2000) mention that communication and knowledge transfer between those responsible for the IT infrastructure management and the Enterprise general managers influences positively on the alignment.

In this sense, Luftman (2000) places a strong emphasis on the idea that it is important to be aware that on some occasions enterprises do not invest on this technological platform mainly because of the lack of communication between both management levels. In addition to this, the model shows the importance of information sharing and communication between the IT and business executives, as an element that enables the strategic alignment process. It also shows the importance of assessing the contribution made by this technological infrastructure on the part of the top management, highlighting the importance of the continuous coordination between the IT and the business strategy in enterprises (Luftman, 2000; Brodbeck et al., 2005). Similarly, Luftman (2000), Brodbeck et al. (2005) and Sledgianowski et al. (2006) agree that value measurement is another important element in this process, as it refers to the strategic and administrative decision making that is carried out in an enterprise when it comes to analyzing and determining the contribution that the IT would make to benefit it.

In this context, Strassmann (1998) argues that a strong emphasis is normally placed on value measurement from a financial perspective. However, Luftman (2000), Palmer and Markus (2000) and Rivard et al. (2006) emphasize the existence of other types of contributions of more qualitative nature. In this respect, Keen (1996) states that 
one of the main contributions that this technology can make to an enterprise is its interconnectivity potential. That is to say, this technological infrastructure has the capability of enabling the information sharing between businesses, or even the possibility of migrating and connecting itself with other information systems within the enterprise and probably with external agents such as suppliers, distributors, customers, among others. Likewise, the governance element makes reference to the process and right to make decisions in the enterprise, on aspects related to the prioritizing of IT projects as well as that on budget and investment control in this technological platform (Brodbeck et al., 2005). In this context, Luftman (2000) mentions that the challenge of these enterprises is to locate those decisions related to the investment on this infrastructure within a framework of equality and importance in relation to other investments. According to Monge et al. (2005), the cost-benefit implications of investing on IT to enable the business processes are essential when deciding on the adoption of such technological resources. This is so because IT investments provide significant benefits (improvements in the strategy, decrease in costs and inventories, market expansion, process efficiency, among others), which are perceived to compensate the investment and maintenance costs. For this reason, it is likely that a higher level management would decide to adopt such infrastructure to enable e-business.

On the other hand, partnership is an element that refers to the capability that enterprise's general managers and those of the IT department to commit them to reciprocally sharing the risks associated with investment decisions, policies and applications of this technology to businesses (Brodbeck et al., 2005; Luftman, 2000; Sledgianowski et al., 2006). In order to attain alignment, the top management needs to collaborate with the IT department in the formal planning of the business strategies and the technology needed to achieve both competitiveness and its successful implementation (Teo and King, 1997). Regarding this, Bruce (1998) points out that the alignment between the business strategies and those of the IT department does not take place in a vacuum, as this requires a strong and independent relationship between both executives at the enterprise. According to Kearns and Lederer (2003), formal planning involves the commitment of both the top management and the management of the IC department to sharing knowledge for the promotion of the alignment process which contributes to the generation of competitive advantage. Similarly, the technological infrastructure is an important element in the strategic alignment process, as it places emphasis on the need to define the assignment of financial resources for the design and scope of its architecture based on the business aims and objectives (Keen, 1996; Sledgianowski et al., 2006).

In this context, Luftman (2000) argues that when analyzing and deciding on the IT investment, it is important to consider the business strategies that these can support, both in the present and in the future. The e-business processes themselves may allow the creation of strategic alliances and the subcontract of processes which are beyond the enterprise's scope. For this reason, collaboration and cooperation among the members of the organization is critical for success. Therefore, it is suggested that the infrastructure should be flexible and integrated by an open team that is able to face the challenges posed by the internal and external environments of an enterprise. Undoubtedly, flexibility is important in order to carry out IT applications adaptations without turning to costly infrastructures. This will enable the migration without major complexities for businesses in volatile business environments characterized by an intense global competition, products with short life cycles, and with costumers who are more sensitive to price, service, and response time issues (Shi and Daniels, 2003).

Finally, human resources are another of the elements within the model of strategic alignment. This means having an organizational culture that is directed towards change and innovation. Furthermore, it is estimated that the adoption and spread of IT is better carried out when the enterprise is prepared and takes steps to anticipate change, mainly because alignment is a process of continuous adaptation (Henderson and Venkatraman, 1993; Sledgianowski et al., 2006). The importance of this element nowadays stems from where change is continuously present. In fact, the experiences employees with IT (for example, percentage of workers using computers, Internet, and information systems in their processes) and the technification of the personnel (programmers, engineers, technicians) is identified as an internal factor that facilitates the adoption of such technological infrastructure in order to enable business processes (Monge et al., 2005). Moreover, any change in the strategy and technology results in a potential change in the values system, the culture, and the structure of the organization's teams. In this process, the human resource plays an important role in the implementation processes and adjustments (Feurer et al., 2000). 


\section{Methodology}

In order to achieve the objectives of this research a quantitative, transactional, exploratory and nonexperimental research design was employed (Hernández, Fernández and Baptista, 2007). For this, the IT/ business strategic alignment models (Henderson and Venkatraman, 1993, 1999; Luftman, 2000) and the alignment maturity criteria (Luftman, 2000; Brodbeck et al., 2005; Sledgianowski et al., 2006) were adopted. The unit of analysis were commercial, services and industrial enterprises located in the northeast region of Mexico. Previous studies have applied the case study in similar investigations (Montiel et al., 2009). According to INEGI $^{5}$ (2004), the Mexican enterprises network was comprised by 4,290,108 economic units. Of this, 85,319 were located in the northeastern region of Mexico (fifty percent commercial, eight percent industrial and the rest to business sector).

\section{Research design}

In order to meet the aims of this research, the IT/business strategic alignment models were adopted (Henderson and Venkatraman, 1993, 1999; Luftman, 2000) as well as the criteria for alignment maturity (Luftman, 2000; Brodbeck et al., 2005; Sledgianowski et al., 2006). The commercial, services and industrial enterprises located in the nor theast of Mexico ${ }^{6}$ were the focus for analysis. According to INEGI (2004), the Mexican entrepreneurship tapestry was made up of 4,290, 108 economic units. Particularly 85,319 were located in the northeast part of Mexico, of which $15 \%$ corresponded to the commercial sector, $8 \%$ to the industrial sector and the rest to services. At a ninety five per cent level of confidence and with a five percent margin of error, the sample obtained was of 383 enterprises. The main informants were intermediate and high level managers of the enterprises located in the northeast part of Mexico (Tamaulipas). The instrument for data collection was a questionnaire made up of 52 Likert scale items of five points, ranging from I (strongly disagree) to 5 (strongly agree). Specifically, 12 of these items (see Appendix I) were included to identify the alignment perspective based on the IT/business strategic alignment model proposed by Henderson and Venkatraman (1993, 1999) and Luftman
(2000). The remaining 40 items (see Appendix II) served to identify the criteria that promote the alignment based on the strategic alignment maturity model (Luftman, 2000; Brodbeck et al., 2005; Sledgianowski et al., 2006).

The field work took place during the months of July, August and September 2009. The response rate was only 23 per cent (90 responses); however, 8 questionnaires were eliminated as they contained unanswered items. Therefore, the final sample was of 82 questionnaires which represented a margin error of 8.32 per cent and were distributed as Table I shows. During the first stage, the data analysis was carried out through descriptive statistics in order to identify the profile of the analyzed enterprises. According to their location, the data analysis reveals that of the analyzed enterprises, $26 \%$ are located in the south zone, $39 \%$ in the central zone and $35 \%$ in the north zone. Based on the economic sector, $60 \%$ belong to the service sector, $20 \%$ to that of commercial and the rest to that of industrial. Similarly, $20 \%$ are small enterprises, $24 \%$ are medium and $56 \%$ are large. Likewise, of the 82 questionnaires obtained, $36 \%$ of the informants performed functional administrative activities, $15 \%$ were accountants of the enterprise, $13 \%$ were responsible for IT area, I3\% were the owners of the Enterprise and 23\% did other activities. Their educational background, $96 \%$ held university degrees and their ages ranged between 21 and 30 years.

\footnotetext{
${ }^{5}$ Informatics, Geography and Statistics National Institute.

${ }^{6}$ State located in the northeast part of Mexico and contributes with a $3.2 \%$ of the GNP. It has international bridges and a harbor.
} 


\begin{tabular}{|c|c|c|c|c|c|}
\hline \multirow{2}{*}{ Size } & \multirow{2}{*}{ Sector } & \multicolumn{3}{c|}{ Zone } & \multirow{2}{*}{ Total } \\
\cline { 3 - 6 } & & South & Center & North & \\
\hline \multirow{2}{*}{ Small (fewer than 10 employees) } & Service & 5 & 5 & 3 & $\mathbf{1 3}$ \\
\cline { 2 - 6 } & Commerce & 1 & 2 & 0 & $\mathbf{3}$ \\
\hline \multirow{2}{*}{ M edium (between 10 and 50 employees) } & Service & 4 & 5 & 2 & $\mathbf{1 1}$ \\
\cline { 2 - 6 } & Commerce & 4 & 4 & 1 & $\mathbf{9}$ \\
\hline \multirow{2}{*}{ L arge (more than 50 employees) } & Service & 3 & 14 & 7 & $\mathbf{2 4}$ \\
\cline { 2 - 6 } & Commerce & 2 & 2 & 2 & $\mathbf{6}$ \\
\cline { 2 - 6 } & Industry & 2 & 0 & 14 & $\mathbf{1 6}$ \\
\hline \multicolumn{2}{|c|}{ TOTAL } & $\mathbf{2 1}$ & $\mathbf{3 2}$ & $\mathbf{2 9}$ & $\mathbf{8 2}$ \\
\hline
\end{tabular}

Table I. Profile of the analyzed enterprises/ Source: Authors

In a later stage, multivariate analysis techniques were used to identify the existing relationship between the e-business alignment perspective and each of the criteria that promotes their maturity with the business strategy. The internal and external validity of the scales were confirmed through the factorial (KMO), the Cronbach Alfa coefficient and the correlations. The 18th version of the SPSS and AMOS software packages were used. Specifically, Table 2 presents the reliability and validity indicators obtained, which fall within the recommended parameters for the $\mathrm{KMO}$ greater than $\mathbf{0 . 7 0}$, the Cronbach Alfa greater than 0.70 and the correlations nearly 1.00 (Segars, 1997; Sledgianowski et al., 2006). The KMO of each of the strategic alignment maturity criteria fall between 8.65 y 9.92 ; the determined Cronbach Alfa falls between a range of 9.16 y 9.47 ; and the total correlation presents positive indicators greater than 0.780 . This provides acceptable reliability and validity indicators for the measurement scales. 


\begin{tabular}{|c|c|c|c|c|c|c|c|c|c|c|c|c|c|}
\hline \multirow{2}{*}{\multicolumn{2}{|c|}{$\begin{array}{c}\text { Alignment } \\
\text { criteria }\end{array}$}} & \multirow{2}{*}{ K MO } & \multirow{2}{*}{$\begin{array}{l}\text { Cron- } \\
\text { Bach } \\
\text { Alpha }\end{array}$} & \multicolumn{10}{|c|}{ Co-relations } \\
\hline & & & & T otal & Com1 & Com2 & Com3 & Com4 & Com5 & Com6 & Com7 & & \\
\hline \multirow{7}{*}{ 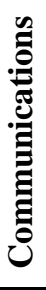 } & Com1 & 0.875 & \multirow{7}{*}{0.911} & 0.818 & 1 & & & & & & & & \\
\hline & Com2 & & & 0.814 & 0.685 & 7 & & & & & & & \\
\hline & 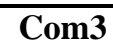 & $\mathrm{Ch}^{2}$ & & 0.805 & 0.583 & 0.683 & 7 & & & & & & \\
\hline & Com4 & 345.71 & & 0.829 & 0.531 & 0.628 & 0.734 & 1 & & & & & \\
\hline & Com5 & & & 0.808 & 0.597 & 0.527 & 0.491 & 0.638 & 1 & & & & \\
\hline & Com6 & Sig. & & 0.811 & 0.640 & 0.566 & 0.567 & 0.569 & 0.689 & 1 & & & \\
\hline & Com7 & 0.000 & & 0.782 & 0.621 & 0.545 & 0.524 & 0.595 & 0.573 & 0.579 & 1 & & \\
\hline \multirow{7}{*}{ 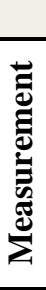 } & & & & T otal & Meal & Mea2 & M ea3 & Mea4 & Mea5 & Mea6 & & & \\
\hline & Meal & 0.884 & \multirow{6}{*}{0.927} & 0.832 & 1 & & & & & & & & \\
\hline & M ea2 & $\mathrm{Ch}^{2}$ & & 0.879 & 0.776 & 1 & & & & & & & \\
\hline & Mea3 & 365.10 & & 0.902 & 0.740 & 0.760 & 1 & & & & & & \\
\hline & M ea4 & & & 0.841 & 0.524 & 0.669 & 0.706 & 1 & & & & & \\
\hline & M ea5 & Sig. & & 0.829 & 0.599 & 0.608 & 0.718 & 0.684 & 1 & & & & \\
\hline & M ea6 & 0.000 & & 0.859 & 0.638 & 0.700 & 0.701 & 0.726 & 0.668 & 7 & & & \\
\hline \multirow{10}{*}{$\begin{array}{l}8 \\
8 \\
8 \\
0 \\
0 \\
0\end{array}$} & & & & T otal & Gov1 & Gov2 & Gov3 & Gov4 & Gov5 & G ov6 & G ov7 & G ov8 & Gov9 \\
\hline & Gov1 & 0.992 & \multirow{9}{*}{0.947} & 0.785 & 1 & & & & & & & & \\
\hline & G ov2 & & & 0.793 & 0.704 & 1 & & & & & & & \\
\hline & Gov3 & $\mathrm{Ch}^{2}$ & & 0.778 & 0.635 & 0.602 & 1 & & & & & & \\
\hline & Gov4 & 643.82 & & 0.888 & 0.635 & 0.593 & 0.689 & 1 & & & & & \\
\hline & Gov5 & & & 0.878 & 0.542 & 0.562 & 0.657 & 0.855 & 1 & & & & \\
\hline & Gov6 & Sig. & & 0.875 & 0.626 & 0.556 & 0.595 & 0.803 & 0.798 & 1 & & & \\
\hline & Gov7 & 0.000 & & 0.871 & 0.604 & 0.584 & 0.555 & 0.790 & 0.805 & 0.836 & 1 & & \\
\hline & Gov8 & & & 0.832 & 0.572 & 0.663 & 0.580 & 0.681 & 0.710 & 0.666 & 0.681 & 1 & \\
\hline & Gov9 & & & 0.843 & 0.616 & 0.716 & 0.558 & 0.648 & 0.686 & 0.720 & 0.709 & 0.709 & 1 \\
\hline \multirow{7}{*}{ 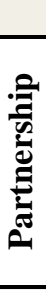 } & & & & T otal & Par1 & Par2 & Par3 & Par4 & Par5 & Par6 & & & \\
\hline & Par1 & 0.908 & \multirow{7}{*}{0.928} & 0.832 & 1 & & & & & & & & \\
\hline & Par2 & $\mathrm{Ch}^{2}$ & & 0.835 & 0.709 & 1 & & & & & & & \\
\hline & Par3 & 354.35 & & 0.905 & 0.682 & 0.692 & 1 & & & & & & \\
\hline & Par4 & & & 0.867 & 0.652 & 0.640 & 0.800 & 1 & & & & & \\
\hline & Par5 & Sig. & & 0.880 & 0.668 & 0.702 & 0.756 & 0.691 & 1 & & & & \\
\hline & Par6 & 0.000 & & 0.826 & 0.594 & 0.575 & 0.713 & 0.658 & 0.710 & 1 & & & \\
\hline \multirow{6}{*}{ 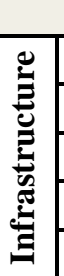 } & & & & T otal & Inf1 & Inf2 & Inf3 & Inf4 & Inf5 & & & & \\
\hline & Inf1 & 0.865 & \multirow{5}{*}{0.916} & 0.804 & 1 & & & & & & & & \\
\hline & Inf2 & $\mathrm{Ch}^{2}$ & & 0.889 & 0.727 & 1 & & & & & & & \\
\hline & Inf3 & 280.68 & & 0.898 & 0.601 & 0.751 & 1 & & & & & & \\
\hline & Inf4 & Sig. & & 0.871 & 0.566 & 0.684 & 0.782 & 1 & & & & & \\
\hline & Inf5 & 0.000 & & 0.859 & 0.600 & 0.671 & 0.729 & 0.722 & 1 & & & & \\
\hline \multirow{8}{*}{$\begin{array}{l}8 \\
8 \\
5 \\
8 \\
8 \\
5 \\
5 \\
5 \\
5\end{array}$} & & & & T otal & Hrl & Hr2 & Hr3 & Hr4 & Hr5 & Hr6 & Hr7 & & \\
\hline & Hr1 & 0.915 & \multirow{7}{*}{0.936} & 0.780 & 1 & & & & & & & & \\
\hline & Hr2 & & & 0.865 & 0.671 & 1 & & & & & & & \\
\hline & Hr3 & $\mathrm{Ch}^{2}$ & & 0.931 & 0.669 & 0.780 & 1 & & & & & & \\
\hline & Hr4 & 465.57 & & 0.793 & 0.489 & 0.587 & 0.740 & 1 & & & & & \\
\hline & Hr5 & & & 0.852 & 0.659 & 0.654 & 0.769 & 0.638 & 1 & & & & \\
\hline & Hr6 & Sig. & & 0.873 & 0.631 & 0.790 & 0.819 & 0.561 & 0.668 & 1 & & & \\
\hline & Hr7 & 0.000 & & 0.878 & 0.602 & 0.722 & 0.785 & 0.651 & 0.691 & 0.768 & 1 & & \\
\hline
\end{tabular}

Table 2. Validity analysis of the strategic alignment dimensions/ Source: Authors 


\section{Results of the alignment of e-business processes and the SMEs strategy in the northeast part of Mexico}

Overall, the evidence obtained from the 82 analyzed enterprises suggests that no relationship exists between the perspective of the e-business processes strategic alignment and the size of the SMEs located in the northeast of Mexico (Table 3). The key informants provide a similar assessment in each of the four perspectives (strategic execution, technological potential, competitiveness potential and service level). In this research, not enough evidence was found to support the argument that the management of the analyzed enterprises perceives a tendency towards a particular perspective of e-business processes alignment and the business strategy because is a dynamic process (Henderson and Venkatraman, 1999; Luftman, 2000). In addition, the alignment can begin in any of the four perspectives, and progress towards another with effective results (Palmer and Markus, 2000).

\begin{tabular}{|c|c|c|c|c|c|c|}
\hline Size & $\mathbf{N}$ & Statistics & Execution & $\begin{array}{l}\text { Technological } \\
\text { potential }\end{array}$ & $\begin{array}{c}\text { Competitiveness } \\
\text { potential }\end{array}$ & Service level \\
\hline \multirow{2}{*}{ Small } & \multirow{2}{*}{16} & M ean & 3.93 & 3.57 & 3.93 & 3.64 \\
\hline & & Typical deviation & 1.00 & 1.16 & 0.62 & 0.93 \\
\hline \multirow{2}{*}{ M edium } & \multirow{2}{*}{20} & M ean & 3.95 & 3.85 & 3.60 & 3.60 \\
\hline & & Typical deviation & 0.69 & 0.81 & 0.82 & 0.82 \\
\hline \multirow{2}{*}{ Large } & \multirow{2}{*}{46} & M ean & 4.35 & 4.08 & 4.02 & 3.85 \\
\hline & & Typical deviation & 0.89 & 0.96 & 1.08 & 0.90 \\
\hline \multirow{2}{*}{ Total } & \multirow{2}{*}{82} & M ean & 4.18 & 3.94 & 3.90 & 3.76 \\
\hline & & Typical deviation & 0.88 & 0.97 & 0.96 & 0.88 \\
\hline \multicolumn{2}{|l|}{ Anova } & $\begin{array}{c}\mathbf{F} \\
\text { Level of significance }\end{array}$ & $\begin{array}{l}2.28 \\
0.11\end{array}$ & $\begin{array}{l}1.64 \\
0.20\end{array}$ & $\begin{array}{l}1.36 \\
0.26\end{array}$ & $\begin{array}{l}0.72 \\
0.49 \\
\end{array}$ \\
\hline Sector & $\mathbf{N}$ & Statistics & Execution & $\begin{array}{c}\text { Technological } \\
\text { potential }\end{array}$ & $\begin{array}{c}\text { Competitiveness } \\
\text { potential }\end{array}$ & Service level \\
\hline \multirow{2}{*}{ Service } & \multirow{2}{*}{48} & M ean & 3.98 & 3.79 & 3.83 & 3.63 \\
\hline & & Typical deviation & 0.93 & 0.97 & 1.00 & 0.82 \\
\hline \multirow{2}{*}{ Commerce } & \multirow{2}{*}{18} & M ean & 4.31 & 4.06 & 3.88 & 3.75 \\
\hline & & Typical deviation & 0.70 & 1.06 & 0.96 & 1.00 \\
\hline \multirow{2}{*}{ Industry } & \multirow{2}{*}{16} & M ean & 4.63 & 4.13 & 4.06 & 4.13 \\
\hline & & Typical deviation & 0.72 & 0.89 & 0.93 & 0.96 \\
\hline \multirow[b]{2}{*}{ Total } & \multirow[b]{2}{*}{82} & M ean & 4.18 & 3.91 & 3.89 & 3.75 \\
\hline & & Typical deviation & 0.88 & 0.97 & 0.97 & 0.89 \\
\hline \multicolumn{2}{|l|}{ Anova } & $\begin{array}{c}\mathbf{F} \\
\text { Level of significance }\end{array}$ & $\begin{array}{l}3.69 \\
0.03\end{array}$ & $\begin{array}{l}0.95 \\
0.39\end{array}$ & $\begin{array}{l}0.33 \\
0.72\end{array}$ & $\begin{array}{l}1.93 \\
0.15\end{array}$ \\
\hline
\end{tabular}

Table 3. Strategic alignment perspective in the analyzed enterprises/ Source: Authors

However, an analysis by economic sector suggests that the only significant difference can be seen in the strategic execution perspective (Table 3 ), as it is more important for the industrial enterprises than it is for the service enterprises $(F=3.69$, Sig. $5 \%$ of confidence level). In a similar way, Luftman (2000) mentions that the strategic execution perspective tends to be the most common one and it is associated with traditional management approaches, where the general manager designs the business strategy, and the IT manager just reacts to provide the IT services needed to support such strategy. This is more complex in the case of industrial enterprises because efficiency in the different production processes is normally required. Based on the analysis of the means of the criteria that promote alignment (communications, measurement, governance, infrastructure, and human resources), it was observed that the management perceives that a high intermediate level of alignment exists 
between the e-business and the business strategy, as the means ranged between 3.55 and 3.8 (Figure 2). According to Sledgianowski et al. (2006), this measure is characterized by management practices and strategic choices that enable a pre-determined alignment level within organizations. $\mathrm{He}$ also argues that the enterprises that fall in this category have a moderate to strong level of strategic alignment maturity (Brodbeck et al., 2005).

Therefore, it was found that the IT management strategy to enable the business processes in the analyzed enterprises includes the operating approaches and participates to a good extent in the strategic management of such infrastructure. This finding is similar to the results obtained by Brodbeck, et al. (2005), with respect to the idea that enterprises tend to find themselves in a functional level of integration. This means that the operating approach to automating processes has moved to the stage of the application of such technologies to integrate the key internal areas of the organization. Nowadays it is relevant to consider that this technology has a paramount role to play in enterprises mainly because it supports the e-businesses in the achievement of operational efficiency. In fact, empirical research conducted in small and medium sized enterprises (Schubert and Leimstoll, 2007) has found a high tendency to use it more to help support activities (accounting, human resources) of the value chain than to the primary ones (marketing, sales, purchasing, and inventory management).

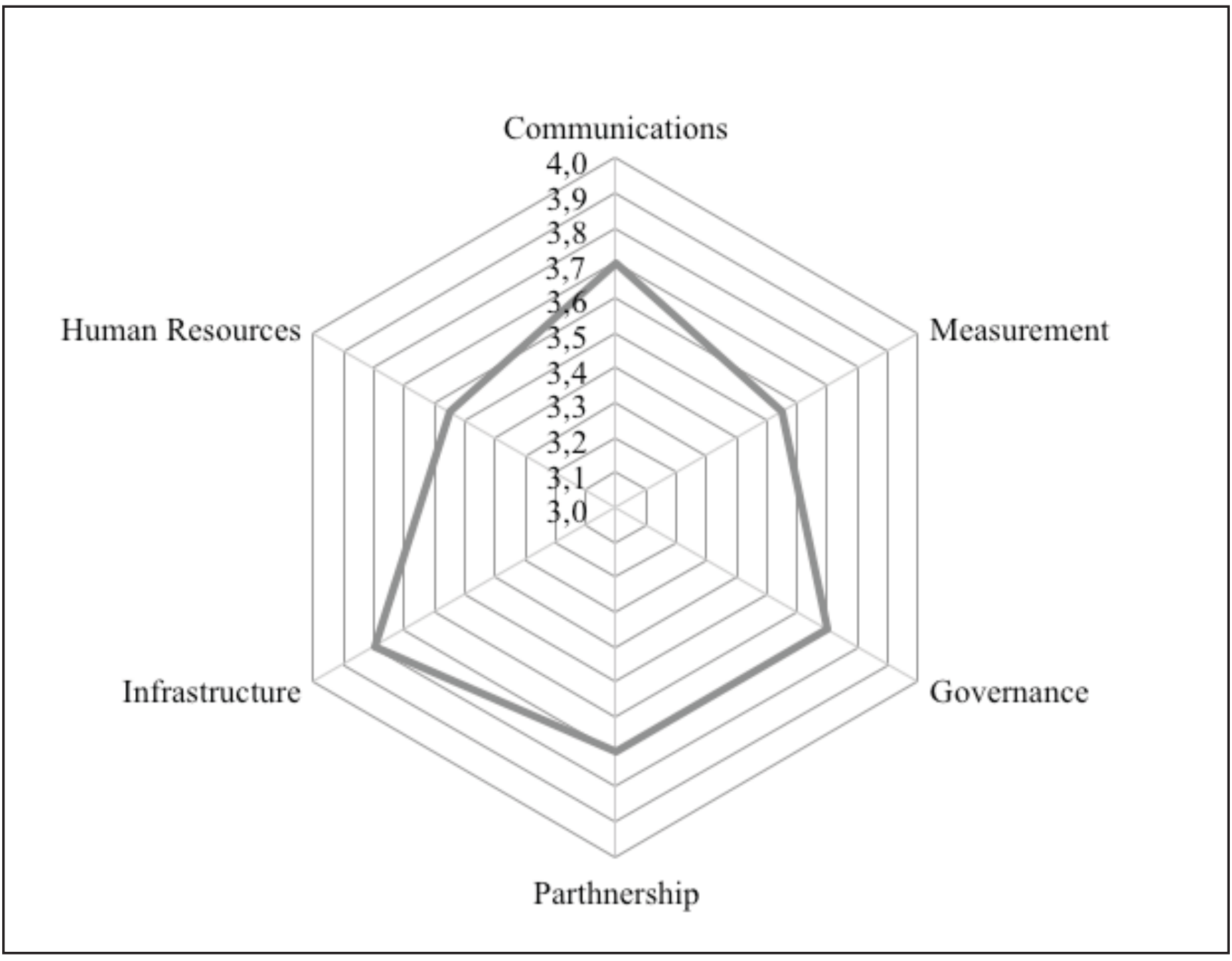

Figure 2. Management' perception level for each criterion that promotes strategic alignment/ Source: Authors 
It is important to note the importance attributed by the informants to each criterion that promotes strategic alignment (Figure 2). The communications, governance and partnership criteria obtained a 3.7 level of alignment maturity on average; the infrastructure criterion apparently obtained the highest level (3.8) of the six elements, while human resources and measurement obtained both the lowest level (3.5). These results go in line with what has been previously stated in the literature (Bruce, 1998;
Reich and Benbasat, 2000; Luftman, 2000; Brodbeck et al., 2005; Peak et al., 2005, Sledgianowski et al., 2006), regarding the importance attached to each of the six criteria (communications, measurement, partnership, governance, infrastructure and human resources) by both IT executives and top managers in enterprises. This is why promoting alignment practices within each one of the aforementioned elements, without neglecting any of them, is of vital relevance.

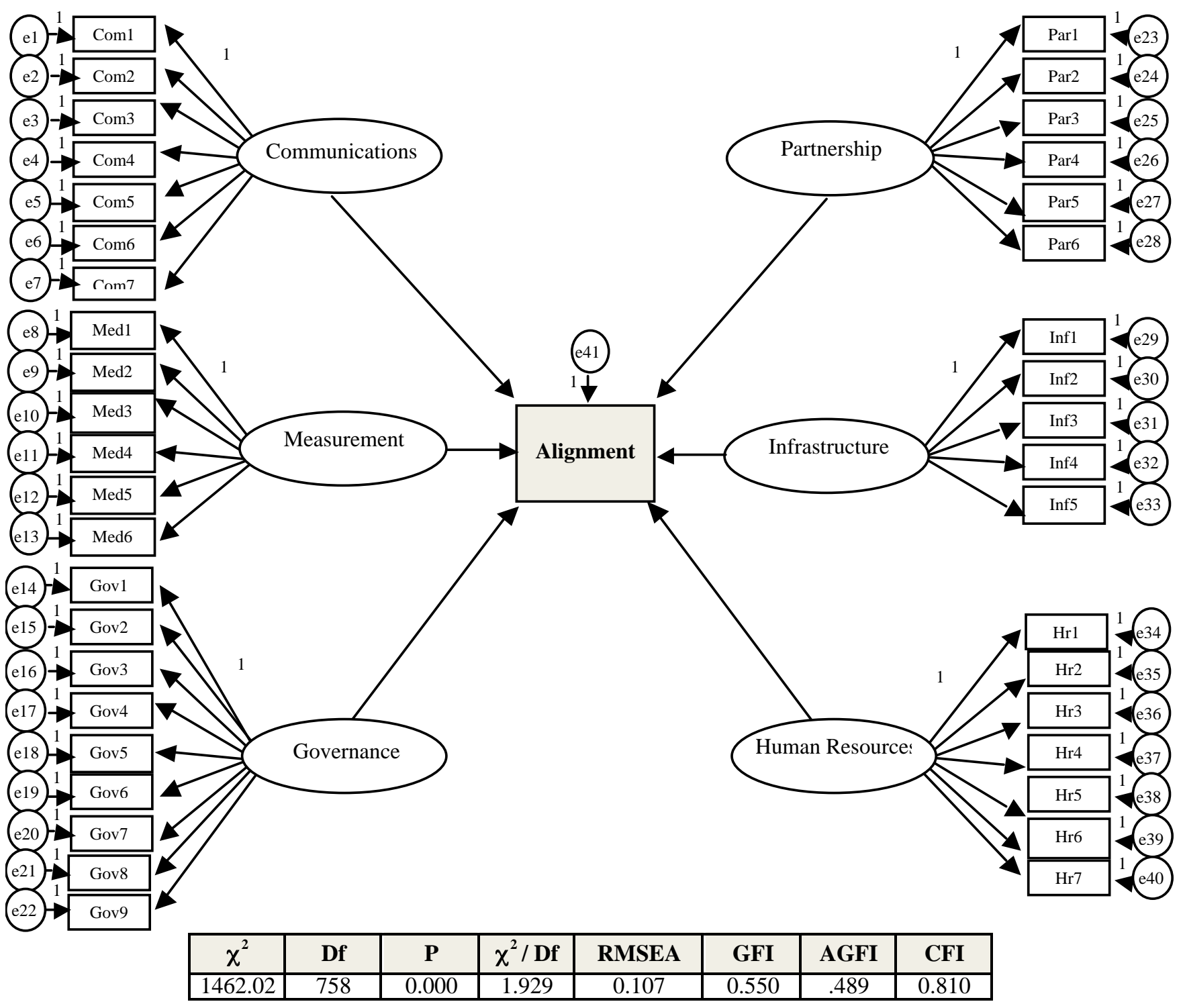

Figure 3. Structural Equations Model for the analysis of the criteria and the strategic alignment perspective of the e-business / Source: Authors 
With respect to the human resources and measurement criteria in which relatively lower values were obtained (Figure 2), it is important to pay attention to both criteria. Regarding the latter, it is common for enterprises to invest in IT; however, they might not define metrics in order to assess the contribution made by such an investment in the organizational performance. Furthermore, sometimes when large enterprises are asked about the contribution that this technology has made to their business, they point out that they are not fully aware of the results since they have no benchmarks with which to compare (Pedraza, 20II). Regarding human resources, it is well known that there is normally resistance on the part of employees when it comes to IT uses to enable business processes. This is more likely to happen when a culture of change and innovation is not promoted. Such a culture is essential because any change in the strategy and technology brings changes in the values system, culture and team work structure (Feurer et al., 2000), specifically because the strategic alignment is a continuous adaptation and change process (Henderson and Venkatraman, 1999; Brodbeck et al., 2005).
Complementarily, the relationship between the elements and the e-business perspective with the business strategy was analyzed though the structural equations model shown in Figure 3. Based on this, the general parameters of the model $[\chi 2=1462.02 ; \mathrm{Df}=758 ; \mathrm{p}<.001$; RMSEA $=0.107 ; \mathrm{GFI}=0.550 ; \mathrm{AGFI}=0.489 ; \mathrm{CFI}=0.8 \mathrm{I} 0]$ fall within the established margins, although they are lower than those obtained by Sledgianowski et al. (2006). This may be due to the sample size (82) as well as the fact that different sectors (commercial, industrial and service) and the enterprise sizes (small, medium and large) were analyzed. However, at the individual level, each item of the dimensions of the elements of the alignment shows positive and significant estimations in relation to its dimension (Appendix III). An analysis of the relationship between the elements and the alignment perspective reveals that the infrastructure $(0.462 ; p<0.001)$, human resources $(0.382 ; \mathrm{p}<0.001)$, communication (0.329; $\mathrm{p}$ $<0.00 \mathrm{I})$ and association $(0.162 ; \mathrm{p}<0.010)$ have positive and significant relationship with the enterprise alignment perspective. However, in this research, the measure $(-0.146 ; p<0.010)$ has a positive and significant impact, whereas there is not enough evidence with respect to the government element to suggest a correlation (Table 4).

\begin{tabular}{|l|c|c|c|c|}
\hline \multirow{2}{*}{$\begin{array}{c}\text { Relationship between the } \\
\text { perspective /alignment criteria }\end{array}$} & \multicolumn{3}{|c|}{ Non-standardized Values } & Standardized V alues \\
\cline { 2 - 5 } & Estimation & Standard error & Probability & E stimation \\
\hline A lignment $\leftarrow$ Communications & 0.222 & 0.059 & $* * *$ & 0.329 \\
\hline A lignment $\leftarrow$ Partnership & 0.121 & 0.063 & $*$ & 0.162 \\
\hline A lignment $\leftarrow$ Governance & 0.071 & 0.061 & & 0.095 \\
\hline A lignment $\leftarrow$ Human Resources & 0.266 & 0.063 & $* * *$ & 0.382 \\
\hline A lignment $\leftarrow$ Infrastructure & 0.345 & 0.071 & $* * *$ & 0.462 \\
\hline Alignment $\leftarrow$ M easurement & -0.088 & 0.050 & $*$ & -0.146 \\
\hline
\end{tabular}

Table 4. Regression between the perspective and the criteria for the strategic alignment of the e-business/ Source: Authors/ Note: $* * * \mathrm{p}<0.001 ; * * \mathrm{p}<0.005 ;{ }^{*} \mathrm{p}<0.010$ 
However, the literature identifies the government as a key criterion, as the alignment involves the good use of decisions related to technological resources for the attainment of strategic, tactic, and operative objectives of the organizations (Peak et al., 2005). As a result of this, it would be relevant to conduct further research in order to deepen the analysis of the impact of this criterion on other indicators which could contribute to the generation and knowledge about the corresponding effects.

\section{Conclusions and recommendations}

The main contribution of the present research in relation to other similar studies is that it analyzed the management view of the existing relationship between the alignment perspective and the elements or criteria that promote this phenomenon within organizations. The first objective of the study was the identification of the strategic alignment perspective. No specific domain was found. On the contrary, the respondents attributed a similar level of importance to the four alignment perspectives (strategy execution, competitiveness potential, technological potential, service level). The second objective was to find out the perception of the elements or criteria that promote alignment within organizations. It was found that the respondents attach a great deal of value to the six elements (communications, measurement, governance, partnership, infrastructure and human resources). This suggests that the analyzed enterprises have a high intermediate profile with respect to the strategic alignment. The third objective was to analyze the relationship between the perspective and the alignment elements. A positive and significant correlation with the communications, infrastructure, human resources, and partnership criteria was found. The measure element has a negative and significant impact, whereas not enough evidence was found to suggest a correlation with the government element.

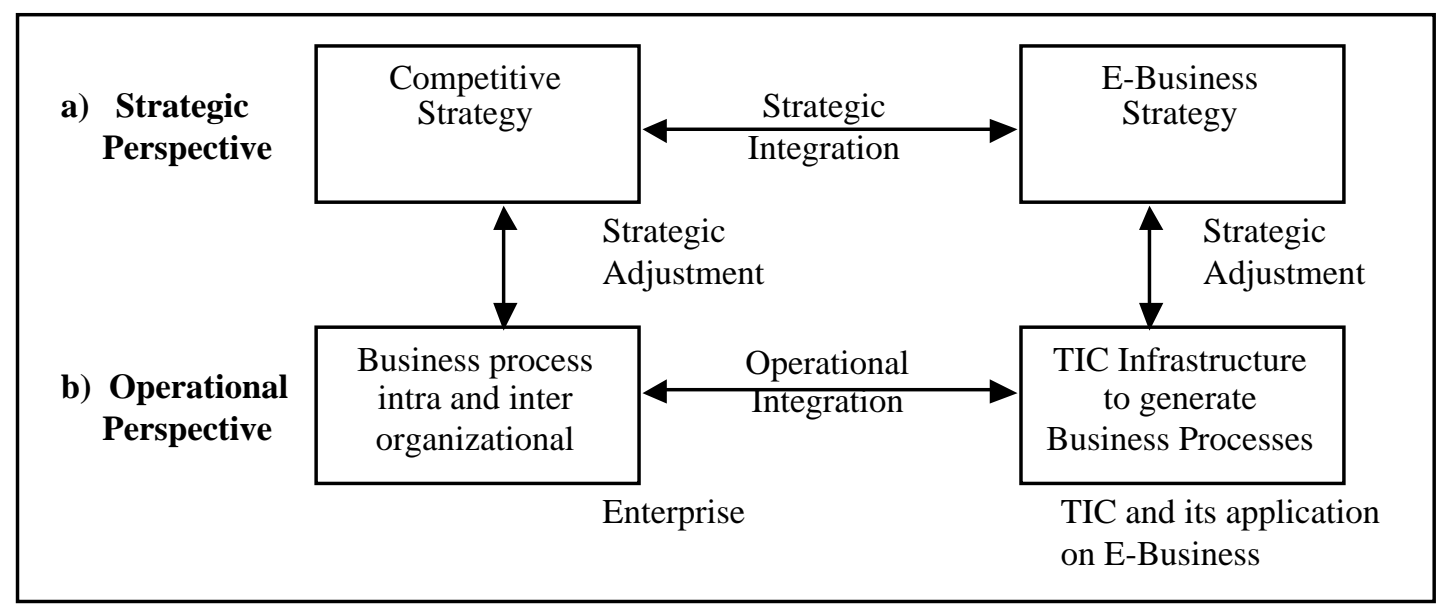

Figure 4. E-Business Strategic Alignment/ Source: Design based on Henderson and Venkatraman (I993 and 1999)

Another contribution of this research is the development of policy proposals aimed at the strategic use of IT to allow the alignment of the business processes and transactions with the business strategies (Figure 4). It is important for the IT management not only to consider its operational effectiveness. It is equally important to promote its strategic application to support the internal processes (accounting, inventories, purchasing, sales, human resources), as well as the external ones (suppliers, customers, government, partners, etc.) through its alignment with the business strategy so as to maximize the benefits and to generate competitive advantage (Kearns and Lederer, 2003). It is, therefore, recommended that both approaches (operational and strategic) be considered as symbiotic guidelines for the incorporation of e-business into enterprises if the investments made in this technology category are to be successful. In order for organizations to view their technological resources as a key factor which will fully support the enterprise strategy (perspective of competitiveness strategy: leadership in costs, differentiation, concentric diversity, etc.), and not only as isolated efforts and investment in the 
organizational areas and functions aimed at obtaining just process efficiency (operational efficiency perspective).

Therefore, this proposal represents a research area for the deep analysis of the strategic alignment phenomenon and its impact on the operational and strategic organizational performance in future studies. The importance attached by the managers to the e-business alignment with the enterprise strategy and the relationship between these elements and the alignment perspective has been made evident in this study. However, it is not only a matter of determining the perception about this phenomenon, which this study has identified as a high intermediate profile. It is also necessary to improve the understanding of the decisions, investments, and uses of such technological infrastructure in order to find not only effectiveness in the execution of processes and transactions, but also the diversification of its key and distinctive capabilities to face their competitors through the appropriate

One of the limitations of this study is the fact that only the perspective of medium and high level managers was considered. It is, therefore, recommended that future studies take into account the top managers' point of view, as they have a high level of authority and responsibility in their organizations with respect to the design and implementation of the enterprise strategy. This, of course, needs to be carried out by drawing on previous research about the phenomenon under analysis (Reich and Benbasat, 2000; Tallon et al., 2000). Another limitation has to do with the low participation rate on the part of the IT managers (13\%). It is therefore, of paramount importance to secure a higher level of participation from this group, as they are considered key informants in the analysis of this phenomenon. Similarly, it would be important to ensure that the participating enterprises have a formal informatics department. Also, a balanced participation of the managers and owners of the participating enterprises and of those responsible for the IT area should be sought. The sample size and the way in which it was calculated in the present study is a limitation to consider in future studies. A more representative sample of the population should be secured in further research in order to strengthen the external validity of the findings. It is important to continue conducting research aimed at identifying specific strategic alignment practices that enterprises in the state of Tamaulipas promote and their impact on the organizational performance from a strategic and operational lens. Further research should also focus on the identification of the factors that enable or disable this process within organizations.

Due to the fact that IT is quite accessible for organizations in today's environment, perhaps the difference may lie in the ability to use such a resource to support the enterprise strategy and even to reinvent it in pursuit of a higher competitiveness position. For example, application systems such as enterprises resources planning (ERP), supply chain management (SCM), customer relationship management (CRM), electronic data exchange, are all types of IT investment that can contribute to generating competitive advantage. This can be possible by aligning the IT with the enterprise strategy (Luftman, 2000; Kearns and Lederer, 2003; Brodbeck, et al., 2005).

\section{About Authors}

Norma Pedraza is professor and researcher in the Business and Administration Faculty at the Autonomous University of Tamaulipas. Her subject research is about alignment of E-Business process and strategic management. She is member of the National Researchers System (SNI) of the National Council of Science and Technology (CONACYT) in Mexico.

Maribel Guerrero is professor and researcher in the Business and Administration Faculty at the Autonomous University of Tamaulipas, and assistant research at the Autonomous University of Barcelona. Her subject research is about entrepreneurship and strategic management. She is member of the National Researchers System (SNI) of the National Council of Science and Technology (CONACYT) in Mexico.

Jesús Lavín is professor and researcher in the Business and Administration Faculty at the Autonomous University of Tamaulipas. His current research is focused on strategic management of public and private organizations. Dr. Lavín is head of the National Association of Business Administration Faculties in Mexico (ANFECA). Also is the head of the Competiveness of Public and Private Organizations Research Group at the Business and Administration Faculty at the Autonomous University of Tamaulipas. He is member of the National Researchers System (SNI) of the National Council of Science and Technology (CONACYT) in Mexico. 


\section{References}

AIAMMARY, J., Fung, C.C. (2008). Knowledge Management Strategic Alignment in the Gulf Cooperation Council Countries. The Electronic Journal of Knowledge Management, 6(2), 75-84.

BEESON, I., Al Mahamid, S., Lane, C. (2003). Survey of strategic alignment indicators in manufacturing companies in the south west of England. http://citeseerx.ist.psu. edu/viewdoc/summary?doi=10.1.I.62.9392 [Accessed on November 10, 2007].

BRODBECK, A., Hoppen, N., Rigoni, E., Canepa, P. (2005). Prácticas de Alinhamento Estratégico Promovidas em organizações do Estado do Rio Grande do Sul.

ANPAD, Associacao Nacional de Pos-Graduacao e Pesquisa em Administracao, UFRGS/ EA / PPGA - XXIX ENANPAD. http://www.anpad.org.br/evento.php?acao=trabalho\&cod edicao subsecao $=30 \&$ cod evento edicao $=9 \& \mathrm{cod}$ edicao trabalho $=9$ [Accessed on March 5, 2007].

BRUCE, K. (1998). Can you align IT with business strategy? Strategy \& Leadership, 26(5), 16-20.

BRYNJOLFSSON, E., Hitt, L. (1995). The Productive Keep Producing - Successful Companies Support Good Business Plans with Right Information Technologies. Information Week, 18, 38-43.

CHAN, Y., Huff, S., Barclay, D., Copeland, D. (1997). Business Strategic Orientation, Information strategic Orientation, and Strategic alignment. Information Systems research, 8(2), 125-150.

CLEMPNER, J., Gutiérrez, A. (2002). Administración y Ejecución de un Plan Estratégico de Tecnología de Información. Revista Digital Universitaria, 3(I), I-I6.

COMPUTER SCIENCES CORPORATION. (2005). Technology issues for financial executives. Annual Report. http://biblioteca.itesm.mx/nav/contenidos_salta 2 . php?col_id=pqd\&loginrandom $=1215189544$ [Accessed on April 23, 2007].

DAVENPORT, T.(1993). Process Innovation, Reengineering Work through Information Technology. Harvard Business School Press, Cambridge.
DEL ÁGUILA, A., Padilla, A. (200I). E-Business y comercio electrónico un enfoque estratégico. Ra-Ma, Spain.

EROSA, V., Arroyo, P. (2003). Una revolución de negocios: Adopción y uso de procesos tecnológicos en México. AMECE, México.

FEURER, R., Chaharbaghi, K., Weber, M., Wargin, J. (2000). Aligning Strategies, Processes, and IT: A Case Study. IEEE Engineering Management Review, I7(I), I-23.

HENDERSON, J., Venkatraman, N. (1993). Strategic alignment: Leveraging information technology for transforming organizations. IBM Systems Journal, 32(I), 4-16.

HENDERSON, J., Venkatraman, N. (1999). Strategic alignment: Leveraging information technology for transforming organizations. IBM Systems Journal, 38(2-3), 472-484.

HERNÁNDEZ, R., Fernández, C., Baptista, P. (2007). Metodología de la Investigación. Mc Graw Hill, México.

INEGI (2004). National Statistics about Economic Units. INEGI, México.

JOHNSTON, D., Wright, L. (2004). The e-business capability of small and medium sized firms in international supply chains. Information Systems and E-Business Management, 2(2-3), 223-240, DOI: 10.1007/sI0257-004-0038-2.

KEARNS, G., Lederer, A. (2003). A resourced-Based View of strategic IT Alignment: How Knowledge Sharing Creates Competitive Advantage. Decision Sciences, 34(I), I-29.

KEEN, P. (1996). Do you need an IT strategy? In: Luftman, J. (Ed.), Competing in the information age. Strategic alignment in practice. Oxford University Press, New York. pp. 2I-42.

KING, W., Teo, T. (1997). Integration between business planning and information systems planning: Validating a stage hypothesis. Decision Sciences, 28(2), 279-308.

LAMBERT, D., Cooper, M. (2000). Issues in supply chain management. Industrial Marketing Management, 29(I), 65-83.

LUFTMAN, J. (2000). Assessing Business-IT Alignment Maturity. Communications of the Association for Information Systems, 4(I4), I-50. 
MARQUES, C., Ferreira, J. (2009). SME Innovative Capacity, Competitive Advantage and Performance in a 'Traditional' Industrial Region of Portugal. Journal of Technology and Management Innovation, 4(4), 53-68.

MONGE, R., Alfaro, C., Alfaro, J. (2005). Tics en las PYMES de Centroamérica: impacto de la adopción y la comunicación en el desempeño de las empresas. Tecnológica de Costa Rica, Costa Rica.

MONTIEL, H., Del Palacio, I., Solé, F., Nuño, P. (2009). Technology Strategy and New Technology Based Firms, Journal of Technology and Management Innovation, 4(4), 42-52.

NIETO, M., Fernández, Z. (2006). The role of information technology in corporate strategy of small and medium enterprises. Journal of International Entrepreneurship, 3(4), 25I-262.

NOOR, A., King, M. (2006). The Alignment of Accounting and Information Systems in SMEs in Malaysia. Journal of Global Information Technology Management, 9(3), 24-42.

PALMER, J., Markus, M. (2000). The Performance Impacts of Quick Response and Strategic Alignment in Specialty Retailing. Information Systems Research, II(3), 24I-259.

PEAK, D., Guynes, C.S., Kroon, V. (2005). Information Technology Alignment Planning - A Case Study. Information \& Management, 42(3), 619-633

PEDRAZA, N. (20II). Alineación Estratégica de Procesos de Negocios Electrónicos. Pearson Education, México.

REICH, B., Benbasat, I. (2000). Factors that influence the social dimension of alignment between business and information technology objectives. MIS Quarterly, 24(I), $8 \mathrm{I}-114$.

RIVARD, S., Raymond, L., Verreault, D. (2006). Resourcebased view and competitive strategy: An integrated model of the contribution of information technology to firm performance. Journal of Strategic Information Systems, I5(I), 29-50.

SCHUBERT, P., Leimstoll, U. (2007). Importance and Use of Information Technology in Small and Medium-Sized Companies. Electronic Markets, I7(I), 38-55
SEGARS, A. (1997). Assessing the unidimensionality of measurement: A paradigm and illustration within the context of information Systems research. Omega, 25(I), |07-|2|.

SHI, D., Daniels, R. (2003). A survey of manufacturing flexibility: Implications for e-business flexibility. IBM Systems Journal, 42(3), 4I4-427.

SLAUGHTER, S., Levien, L., Ramesh, B., Pries-Heje, J., Baskerville, R. (2006). Aligning Software Processes with Strategy. MIS Quarterly, 30(4), 891-918.

SLEDGIANOWSKI, D., Luftman, J., Reilly, R. (2006). Development and Validation of an Instrument to Measure Maturity of IT Business Strategic Alignment Mechanisms. Information Resources Management Journal, 19(3), I8-32.

STRASSMANN, P. (1998). What is Alignment? Alignment is The Delivery of the Required Results. Cutter IT Journal. http://www.strassmann.com/pubs/alignment/ [Accessed on March I5, 2007].

TALLON, P., Kraemer, K. L., Gurbaxani, V. (2000). Executives' perceptions of the business value of information technology: A process-oriented approach. The Journal of Strategic Information Systems, 16(4), 145-173.

TEO, T., King, W. (1997). Integration between business planning and information systems planning: An evolutionary-contingency perspective. Journal of Management Information Systems, 14(I), 185-214.

TORKZADEH, G., Koufteros, X., Doll, W.J. (2005). Confirmatory Factor Analysis and Factorial Invariance of the Impact of Information Technology Instrument. Omega, 33(2), 107-II8 


\section{Appendix I. Items related to strategic alignment}

\begin{tabular}{|c|c|c|}
\hline \multicolumn{2}{|c|}{ Alignment Perspective } & Description \\
\hline \multirow{3}{*}{$\begin{array}{l}\text { Strategic } \\
\text { Execution }\end{array}$} & XEJEC1 & The business manager develops strategies based on the business characteristics. \\
\hline & XEJEC2 & The IT manager projects and implements IT solutions. \\
\hline & XEJEC3 & $\begin{array}{l}\text { The technology performance such as information systems and the Internet is assessed based } \\
\text { on financial criteria. }\end{array}$ \\
\hline \multirow{3}{*}{$\begin{array}{l}\text { Technological } \\
\text { Potential }\end{array}$} & POTTEC1 & $\begin{array}{l}\text { The business manager perceives technology solutions such as information systems and the } \\
\text { internet as opportunities for business }\end{array}$ \\
\hline & POTTEC2 & The IT manager manages to provide solutions in practical areas foreseen by the organizations. \\
\hline & POTTEC3 & $\begin{array}{l}\text { Technologies such as information systems, the Internet are assessed based on their } \\
\text { technological leadership compared to other enterprises }\end{array}$ \\
\hline \multirow{3}{*}{$\begin{array}{l}\text { Competitiveness } \\
\text { Potential }\end{array}$} & POTCOM 1 & $\begin{array}{l}\text { The business manager perceives new opportunities for business through the use of } \\
\text { technologies such as information systems and the Internet. }\end{array}$ \\
\hline & РОТСОМ 2 & The IT manager identifies market trends to aid the organization. \\
\hline & POTCOM 3 & IT is assessed based on the quality of its solutions. \\
\hline \multirow{3}{*}{ Service level } & SER 1 & The business manager prioritizes the assignment of resources for the IT infrastructure. \\
\hline & SER 2 & $\begin{array}{l}\text { The IT manager develops an IT strategy independent of the business strategy aimed at } \\
\text { attaining excellence in the quality of their services. }\end{array}$ \\
\hline & SER 3 & The IT area is assessed based on the level of its usersÕsatisfaction. \\
\hline
\end{tabular}

Source: Henderson and Venkatraman (1993, 1999), Luftman (2000) 


\section{Appendix II. Items related to the criteria for the e-business strategic alignment}

\begin{tabular}{|c|c|c|}
\hline \multicolumn{2}{|c|}{$\begin{array}{l}\text { Alignment } \\
\text { Criteria }\end{array}$} & Description \\
\hline \multirow{7}{*}{ 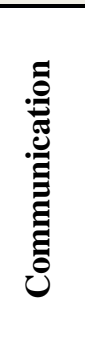 } & Com1 & The members of the IT area develop a good understanding of the business. \\
\hline & Com2 & The business management has a good understanding of the e-business. \\
\hline & Com3 & The staff has a good understanding of the e-business in the enterprise. \\
\hline & Com4 & All the business team is required to have a good understanding of the e-business. \\
\hline & Com5 & $\begin{array}{l}\text { There are effective formal and standardized methods promoted by the business management for learning in the } \\
\text { organization. }\end{array}$ \\
\hline & Com6 & There is easy access to the different areas of the business and the business systems \\
\hline & Com7 & $\begin{array}{l}\text { There is knowledge sharing (intellectual understanding and problems/opportunities appreciation, etc.) between } \\
\text { those responsible for the e-business and the business processes }\end{array}$ \\
\hline \multirow{6}{*}{ 递 } & M ed1 & $\begin{array}{l}\text { The business has methods and procedures to determine the contribution of the e-business to technical, financial, } \\
\text { operational and human aspects. }\end{array}$ \\
\hline & M ed2 & The e-business methods and the corporative processes are fully integrated in the Enterprise. \\
\hline & M ed3 & $\begin{array}{l}\text { There are procedures in place to measure the quality of the services offered by the electronic processes that serve } \\
\text { as feedback. }\end{array}$ \\
\hline & M ed4 & $\begin{array}{l}\text { It is normal for enterprises to engage in formal benchmarking practices. There is a regulated process to take } \\
\text { action and measure changes. }\end{array}$ \\
\hline & M ed5 & There are ongoing improvement measures and effectiveness measurement practices in place. \\
\hline & M ed6 & $\begin{array}{l}\text { There is evidence in the enterprise that the e-business functions have contributed to the achievement of the } \\
\text { strategic organizational aims. }\end{array}$ \\
\hline \multirow{9}{*}{$\begin{array}{l}\text { है } \\
\text { है } \\
\text { ह } \\
8 \\
0\end{array}$} & Gov1 & $\begin{array}{l}\text { We do a formal strategic planning of the business in the functional unit, through the organization and with our } \\
\text { business partners and alliances }\end{array}$ \\
\hline & Gov2 & $\begin{array}{l}\text { We do a formal strategic planning of the e-business in the functional unit, through the collaboration with the } \\
\text { business management. }\end{array}$ \\
\hline & Gov3 & The IT area is present in the formal organizational structure and has well-defined functions. \\
\hline & Gov4 & In the Enterprise, the e-businesses are treated as investment. \\
\hline & Gov5 & In the Enterprise, the e-businesses are a utility center for the generation of profit. \\
\hline & Gov6 & The e-businesses are view ed as a process catalyzes, and business strategy facilitators. \\
\hline & Gov7 & $\begin{array}{l}\text { In the Enterprise, the e-businesses are meant to create competitive advantage and maximize profit. Our business } \\
\text { partners perceive their value. }\end{array}$ \\
\hline & Gov8 & $\begin{array}{l}\text { Committee meetings take place in a regular and formal basis which are highly effective and include decision- } \\
\text { making strategies }\end{array}$ \\
\hline & Gov9 & The IT area of the Enterprise responds promptly to the business organizational change needs. \\
\hline \multirow{6}{*}{$\begin{array}{l}\frac{0}{2} \\
\frac{10}{4} \\
\frac{5}{0} \\
8\end{array}$} & Par1 & E-businesses are view ed as partner that adds value to the Enterprise. \\
\hline & Par2 & The e-businesses adapt themselves to the Enterprise in order to aid in the attainment of its strategic objectives. \\
\hline & Par3 & $\begin{array}{l}\text { The risks and benefits associated with the use of the e-businesses are shared between the IT area and the business } \\
\text { managers. }\end{array}$ \\
\hline & Par4 & $\begin{array}{l}\text { In relation to the above question, there is a formal system of compensation and rewards in place that incentivizes } \\
\text { the managers to take risks. }\end{array}$ \\
\hline & Par5 & There is a sense of trust between the IT area and the Enterprise. \\
\hline & Par6 & Support is provided to the IT area by a superior level and the administration board. \\
\hline \multirow{5}{*}{ 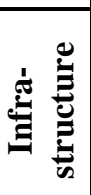 } & Inf1 & Our primary systems are facilitators/promoters of the business strategy. \\
\hline & $\operatorname{lnf2}$ & The e-businesses are a means to make changes in the business strategy. \\
\hline & $\operatorname{lnf3}$ & Our IT standards are defined and applied to the entire Enterprise. \\
\hline & $\operatorname{lnf} 4$ & The IT is adequate and integrated to support the e-businesses. \\
\hline & $\operatorname{lnf5}$ & Our IT infrastructure is a resource used to enable and manage the prompt response to the changes in the market. \\
\hline \multirow{7}{*}{ 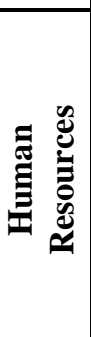 } & Rh1 & An entrepreneurial spirit is promoted in our Enterprise. \\
\hline & Rh2 & $\begin{array}{l}\text { The important decisions related to e-businesses made by the managers are based on the advice given by the IT } \\
\text { area. }\end{array}$ \\
\hline & Rh3 & The change preparation programs are available throughout the Enterprise and can be anticipated \\
\hline & Rh4 & There is a position rotation in the Enterprise as a strategy to promote continued learning. \\
\hline & Rh5 & There are formal training programs in place at the Enterprise. \\
\hline & Rh6 & Trust between the IT staff and the staff of the other business areas has been achieved. \\
\hline & Rh7 & $\begin{array}{l}\text { There are formal programs designed to attract and retain the best professionals (with technical and business skills) } \\
\text { in the IT area. }\end{array}$ \\
\hline
\end{tabular}

Source: Luftman (2000), Brodbeck et al. (2005), Sledgianowski et al. (2006) 
Appendix III. Estimation of the elements of the e-business strategic alignment

\begin{tabular}{|c|c|c|c|c|c|c|c|c|c|c|c|}
\hline \multicolumn{3}{|c|}{$\begin{array}{c}\text { Indicators } \\
\text { Relationships }\end{array}$} & Estimation & $\begin{array}{c}\text { Standard } \\
\text { E rror }\end{array}$ & $\begin{array}{l}\text { Proba- } \\
\text { bility }\end{array}$ & \multicolumn{3}{|c|}{$\begin{array}{c}\text { Indicators } \\
\text { Relationships }\end{array}$} & E stimation & \multirow[t]{2}{*}{$\begin{array}{c}\text { Standard } \\
\text { Error }\end{array}$} & \multirow[t]{2}{*}{$\begin{array}{r}\text { Proba } \\
\text { bility }\end{array}$} \\
\hline Com1 & $<--$ & \multirow{7}{*}{ 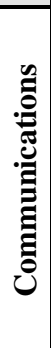 } & 1.000 & & & $\operatorname{lnf1}$ & $<<--$ & \multirow{5}{*}{ 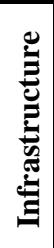 } & 1.000 & & \\
\hline Com2 & $<--$ & & 1.006 & 0.137 & $* * *$ & $\operatorname{lnf2}$ & $<--$ & & 1.253 & 0.162 & $* * *$ \\
\hline Com3 & $<--$ & & 0.981 & 0.141 & $* * *$ & $\operatorname{lnf3}$ & $<--$ & & 1.346 & 0.163 & $* * *$ \\
\hline Com4 & $<--$ & & 1.078 & 0.137 & $* * *$ & $\operatorname{lnf} 4$ & $<--$ & & 1.200 & 0.158 & $* * *$ \\
\hline Com5 & $<--$ & & 1.269 & 0.164 & $* * *$ & Inf5 & $<--$ & & 1.150 & 0.150 & $* * *$ \\
\hline Com6 & $<---$ & & 0.995 & 0.129 & $* * *$ & Par1 & $<--$ & \multirow{6}{*}{ 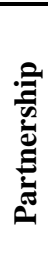 } & 1.000 & & \\
\hline Com7 & $<--$ & & 1.014 & 0.139 & $* * *$ & Par2 & $<--$ & & 1.015 & 0.122 & $* * *$ \\
\hline M eal & $<<--$ & \multirow{6}{*}{ है } & 1.000 & & & Par3 & $<<--$ & & 1.186 & 0.130 & $* * *$ \\
\hline M ea2 & $<<--$ & & 1.032 & 0.107 & $* * *$ & Par4 & $<--$ & & 1.152 & 0.132 & $* * *$ \\
\hline M ea3 & $<--$ & & 1.126 & 0.108 & $* * *$ & Par5 & $<--$ & & 1.155 & 0.123 & $* * *$ \\
\hline M ea4 & $<<--$ & & 0.966 & 0.119 & $* * *$ & Par6 & $<--$ & & 1.047 & 0.126 & $* * *$ \\
\hline M ea5 & $<--$ & & 0.900 & 0.108 & $* * *$ & Gov1 & $<--$ & \multirow{9}{*}{ 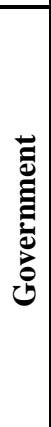 } & 1.000 & & \\
\hline M ea6 & $<--$ & & 0.914 & 0.104 & $* * *$ & Gov2 & $<--$ & & 1.047 & 0.127 & $* * *$ \\
\hline $\mathrm{Hrl}$ & $<--$ & \multirow{7}{*}{ 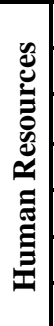 } & 1.000 & & & Gov3 & $<--$ & & 1.054 & 0.161 & $* * *$ \\
\hline $\mathrm{Hr} 2$ & $<--$ & & 1.173 & 0.146 & $* * *$ & Gov4 & $<--$ & & 1.277 & 0.160 & $* * *$ \\
\hline $\mathrm{Hr} 3$ & $<---$ & & 1.331 & 0.150 & $* * *$ & Gov5 & $<--$ & & 1.285 & 0.161 & $* * *$ \\
\hline $\mathrm{Hr} 4$ & $<---$ & & 1.239 & 0.185 & *** & Gov6 & $<--$ & & 1.279 & 0.160 & $* * *$ \\
\hline $\mathrm{Hr} 5$ & $<--$ & & 1.238 & 0.163 & $* * *$ & Gov7 & $<--$ & & 1.284 & 0.162 & $* * *$ \\
\hline $\mathrm{Hr6}$ & $<--$ & & 1.278 & 0.153 & $* * *$ & Gov8 & $<--$ & & 1.173 & 0.166 & $* * *$ \\
\hline $\mathrm{Hr} 7$ & $<<--$ & & 1.377 & 0.172 & $* * *$ & Gov9 & $<--$ & & 1.158 & 0.158 & $* * *$ \\
\hline
\end{tabular}

Note: $* * * p<0.001 ; * * p<0.005 ; * p<0.010$ 
J. Technol. Manag. Innov. 20II,Volume 6, Issue 4 